\title{
Corrigendum to "A Review on the Control of Second Order Underactuated Mechanical Systems"
}

\author{
Soukaina Krafes (D), Zakaria Chalh (D), and Abdelmjid Saka \\ Ingénierie, Systèmes et Applications Laboratory, Sidi Mohammed Ben Abdellah, Fez, Morocco \\ Correspondence should be addressed to Soukaina Krafes; soukaina.krafes@usmba.ac.ma \\ Received 13 June 2020; Accepted 15 June 2020; Published 17 July 2020 \\ Copyright (c) 2020 Soukaina Krafes et al. This is an open access article distributed under the Creative Commons Attribution \\ License, which permits unrestricted use, distribution, and reproduction in any medium, provided the original work is \\ properly cited.
}

The article titled "A Review on the Control of Second Order Underactuated Mechanical Systems" [1] was found to contain material from published work, which was not cited. The earlier article is as follows:

Yang Liu and Hongnian Yu, "A survey of underactuated mechanical systems," IET Control Theory \& Applications, vol. 7, no. 7, pp. 921-935, 2 May 2013, doi: 10.1049/ietcta. 2012.0505 https://ieeexplore.ieee.org/document/6562926/ [2].

Figures 1-6 are conceptually the same as Figures 1-4 and $5-7$, respectively. Table 1, showing the equations of motion for underactuated mechanical systems, is the same as Table 1 in the earlier article. The same eight examples of underactuated systems are shown in Section 2 and Section 2.2 in the earlier article. Section 3 and Section 2.1 are similar, and the titles of Sections 4 and 5 versus Sections 3 and 4 are the same: "Classification of Underactuated Mechanical Systems" and "Control of Underactuated Mechanical Systems" versus "Classification of UMS" and "Control of UMS." The contents of Section 5 in both articles are similar, and Section 6.1 on "Intelligent Controller (Fuzzy Logic)" is similar to Section 4.4 on "Fuzzy Control" in the earlier article.

The authors apologize for this.

\section{References}

[1] S. Krafes, Z. Chalh, and A. Saka, "A review on the control of second order underactuated mechanical systems," Complexity, vol. 2018, Article ID 9573514, 17 pages, 2018.

[2] Y. Liu and H. Yu, "A survey of underactuated mechanical systems," IET Control Theory \& Applications, vol. 7, no. 7, pp. 921-935, 2013. 